OPEN ACCESS

Edited by:

Thierry Hauet,

University of Poitiers, France

Reviewed by: Humberto Machado,

Centro Hospitalar Universitário Do

Porto, Portugal

Basma Mohamed,

University of Florida, United States

*Correspondence:

Zhe Feng

zhezhe_4025@126.com

Specialty section:

This article was submitted to

Nephrology,

a section of the journal

Frontiers in Medicine

Received: 02 August 2021 Accepted: 09 December 2021 Published: 24 December 2021

Citation:

Yu X and Feng Z (2021) Analysis of Risk Factors for Perioperative Acute Kidney Injury and Management Strategies. Front. Med. 8:751793. doi: 10.3389/fmed.2021.751793

\section{Analysis of Risk Factors for Perioperative Acute Kidney Injury and Management Strategies}

\author{
Xiang Yu and Zhe Feng* \\ State Key Laboratory of Kidney Diseases, Department of Nephrology, National Clinical Research Center of Kidney Diseases, \\ Chinese PLA Institute of Nephrology, Chinese PLA General Hospital, Beijing, China
}

Acute kidney injury (AKI) is a serious clinical syndrome, and one of the common comorbidities in the perioperative period. AKI can lead to complications in surgical patients and is receiving increasing attention in clinical workup. In recent years, the analysis of perioperative risk factors has become more in-depth and detailed. In this review, the definition, diagnosis, and pathophysiological characteristics of perioperative $\mathrm{AKI}$ are reviewed, and the main risk factors for perioperative $\mathrm{AKI}$ are analyzed, including advanced age, gender, certain underlying diseases, impaired clinical status such as preoperative creatinine levels, and drugs that may impair renal function such as non-steroidal anti-inflammatory drugs (NASIDs), ACEI/ARB, and some antibiotics. Injectable contrast agents, some anesthetic drugs, specific surgical interventions, anemia, blood transfusions, hyperglycemia, and malnutrition are also highlighted. We also propose potential preventive and curative measures, including the inclusion of renal risk confirmation in the preoperative assessment, minimization of intraoperative renal toxin exposure, intraoperative management and hemodynamic optimization, remote ischemic preadaptation, glycemic control, and nutritional support. Among the management measures, we emphasize the need for careful perioperative clinical examination, timely detection and management of AKI complications, administration of dexmedetomidine for renal protection, and renal replacement therapy. We aim that this review can further increase clinicians' attention to perioperative AKI, early assessment and intervention to try to reduce the risk of $\mathrm{AKI}$.

Keywords: AKI, perioperative, risk factors, prevention, management

\section{INTRODUCTION}

Acutekidney injury (AKI) is a common clinical syndrome characterized by a sudden and persistent decline in kidney function over hours to days. It has numerous etiologies and complex mechanisms. AKI has received increasing attention from clinicians as one of the major perioperative comorbidities. Studies have reported the incidence of in-hospital AKI to be $2-18 \%$ in perioperative patients and $22-57 \%$ in intensive care patients (1). Perioperative AKI can lead to increased mortality, incidence of chronic kidney disease (CKD) and risk of postdischarge hemodialysis (HD), as well as increased healthcare costs and resource utilization $(2,3)$. Therefore, the concept of perioperative AKI should be explored in depth, and the associated risk factors should be analyzed to enhance the prediction and assessment of AKI, intervene in advance, and try to reduce the severity of AKI when it occurs. 


\section{DEFINITION AND DIAGNOSIS OF PERIOPERATIVE AKI}

Perioperative AKI is defined as an acute decline in renal function occurring from 5-7 d before to 7-12 d after surgery (4), but there is no standard definition of AKI, resulting in a lack of clarity in clinical workup. The consensus for AKI was set in the 2002 RIFLE criteria with reference to $\mathrm{sCr}$ values and urine volume. The revised RIFLE criteria were published by AKIN in 2005, the main changes being the recognition that small changes in $\mathrm{sCr}$ values may increase morbidity and mortality and allowing AKI to be defined without knowledge of baseline sCr. In 2012, KDIGO proposed clinical practice guidelines for AKI, giving an updated definition of blood creatinine $\geq 26.5 \mathrm{mmol} / \mathrm{L}$ within $48 \mathrm{~h}$, blood creatinine $\geq 1.5$ times the basal level within $7 \mathrm{~d}$ or urine output $<0.5 \mathrm{~mL} / \mathrm{kg} / \mathrm{h}$ for $6 \mathrm{~h} \mathrm{(5)} \mathrm{(Table} \mathrm{1).} \mathrm{However,} \mathrm{these} \mathrm{criteria} \mathrm{still}$ have drawbacks. First, the perioperative period has been shown to be a unique environment where stress and hypovolemia cause frequent intraoperative and postoperative reductions in urine output. During surgery, only $5-15 \%$ of the crystalloid volume load is excreted from the urine, compared to $40-75 \%$ in nonanesthetized patients $(6,7)$. The same is true for $\mathrm{sCr}$, which has a relative lag, and it changes after $50 \%$ of the kidney function is impaired. Serum creatinine may also be influenced by a variety of factors, including ethnicity, age, sex, chronic disease, nutrition, volume overload, body mass, and muscle trauma (8).

Recent research on biomarkers that contribute to the early diagnosis of AKI has made important advances. Target biomarkers require that they be released and detectable in blood or urine before an increase in $\mathrm{s} C r$ and/or a decrease in urine output, with the aim of detecting subclinical AKI before kidney tissue damage and functional decline $(9,10)$. Different markers may be associated with different parts of the kidney and different mechanisms of injury, so the detection of AKI biomarkers not only allows the early detection of subclinical AKI but also helps to determine the cause and implement specific treatment. The functional markers neutrophil gelatinaseassociated lipoprotein (NGAL) and liver-fatty acid binding protein (L-FABP) have been approved for use in Europe and Japan, respectively, while the combination of the cell cycle markers tissue inhibitor of metalloproteinase 2 (Timp-2) and insulin-like growth factor binding protein-7 (IGFBP7) have also been approved by the US FDA (11). Other target molecules include kidney injury molecule-1 (KIM-1), interleukin 18 (IL18 ), calprotectin (CALPRO), $\beta 2$-microglobulin ( $\beta 2-\mathrm{MG})$, total urinary protein (UTP), microRNAs, etc (12-17). These markers have been well-studied, but their clinical predictive power is still unsatisfactory, and studies are being conducted with artificial intelligence to construct AKI prediction models, which will be more rational and effective when applied along with biomarkers as important parameters.

\section{PATHOPHYSIOLOGY}

Inadequate perfusion is the main mechanism affecting renal function, and all causes of decreased mean arterial pressure
(MAP) can lead to renal hypoperfusion. Initially, the kidney can maintain GFR by activating the sympathetic nervous system, including the release of vasopressin (ADH) and angiotensin II (ANG II), activating the renin-angiotensin-aldosterone system (RAAS), with the end result of water and sodium retention to maintain GFR. Next, if the renal perfusion deficit is not corrected in time, angiotensin II eventually causes vasoconstriction of afferent and efferent small arteries, which decreases GFR. These mechanisms work only if MAP is kept above the autoregulatory threshold; below $75-80 \mathrm{mmHg}$, the efficiency of autoregulation decreases sharply.

Along with a deeper understanding of the mechanisms of AKI occurrence, it was found that a purely ischemic model does not explain sepsis and major surgery-related AKI well. The hemodynamics of sepsis can be predominantly hyperdynamic, and overall renal blood flow may remain constant or increase, but the glomerular filtration rate decreases significantly. In addition, perioperative AKI is caused not by a single factor but by multiple insults. Reduced perfusion may not be the only cause of surgery-related AKI, as partial occlusion of the renal artery for a certain period of time can also be tolerated by the kidney, and it is now believed that systemic inflammatory response syndrome (SIRS) is a non-specific response of the body to surgical trauma through microcirculatory dysfunction, intrinsic repair mechanism abnormalities, inflammation- and immunemediated injury, and endothelial cell dysfunction, resulting in a combined response that leads to AKI (18).

\section{RISK FACTORS}

\section{Impaired Clinical Status}

Along with advances in surgical techniques, anesthesia techniques, and related care monitoring technologies, surgery in high-risk elderly patients is being performed more and more often. Comorbidities, acute illnesses and age-related decline in physiological reserve have led to an increased risk of perioperative AKI in surgical patients. From the large amount of prospective data on surgical patients, the identifiable risk factors for AKI are age $\geq 56$ years, male sex, active congestive heart failure, ascites, hypertension, preoperative creatinine $>106$ $\mathrm{mol} / \mathrm{L}$, diabetes mellitus (controlled by oral medications or insulin injections) (19-24), and patients with six or more risk factors have an increased incidence and hazard ratio of AKI (25). Additional risk factors include ventilator dependence, chronic obstructive pulmonary disease, smoking, coagulation disorders, cancer, obesity, and long-term steroid medication use $(26,27)$ (Table 2).

\section{Drugs That Impair Kidney Function}

Many drugs routinely used in the perioperative period may adversely affect renal function, and it is now believed that up to $25 \%$ of cases of severe AKI are triggered by nephrotoxic drugs (Table 2). Non-steroidal anti-inflammatory drugs (NSAIDs) can directly reduce renal blood flow while causing tubular obstruction through crystal deposition and can induce direct cytotoxicity and cell-mediated immune damage mechanisms, leading to acute kidney injury (AKI). Risk 
TABLE 1 | AKI diagnostic criteria.

\begin{tabular}{|c|c|c|c|c|}
\hline \multirow[t]{2}{*}{ Staging } & \multirow[t]{2}{*}{ Urine volume } & \multicolumn{3}{|l|}{ Diagnostic criteria } \\
\hline & & RIFLE (2002) & AKIN (2005) & KIDGO (2012) \\
\hline 1 issue & $\begin{array}{l}\text { Urine output } \\
<0.5 \mathrm{ml} / \mathrm{kg} / \mathrm{h} \\
>6 \mathrm{~h}\end{array}$ & $\begin{array}{l}\text { Risk: } \mathrm{sCr} \text { elevated > } \\
1.5 \text { times } \\
\text { or GFR decline > 25\% }\end{array}$ & $\begin{array}{l}\mathrm{sCr} \text { elevated } \geq 26.4 \\
\mu \mathrm{mol} / \mathrm{L} \\
\text { or elevated }>1.5-2.0 \text { times } \\
\text { the baseline value }\end{array}$ & $\begin{array}{l}\mathrm{sCr} \text { elevated } \geq 26.5 \mu \mathrm{mol} / \mathrm{L} \\
(0.3 \mathrm{mg} / \mathrm{dl}) \text { or elevated }> \\
1.5-1.9 \text { times the baseline } \\
\text { value }\end{array}$ \\
\hline 2 issues & $\begin{array}{l}\text { Urine output } \\
<0.5 \mathrm{ml} / \mathrm{kg} / \mathrm{h} \\
>12 \mathrm{~h}\end{array}$ & $\begin{array}{l}\text { Injury: } \mathrm{sCr} \\
\text { elevated }>2 \text { times } \\
\text { or GFR decline }>50 \%\end{array}$ & $\begin{array}{l}\text { sCr elevation }>2.0-3.0 \\
\text { times the baseline value }\end{array}$ & $\begin{array}{l}\text { Elevation }>2.0-2.9 \text { times } \\
\text { the baseline value }\end{array}$ \\
\hline 3 issues & $\begin{array}{l}\text { Urine output } \\
<0.3 \mathrm{ml} / \mathrm{kg} / \mathrm{h} \\
>24 \mathrm{~h} \\
\text { or no urine for } \\
>12 \mathrm{~h}\end{array}$ & $\begin{array}{l}\text { Failure: } \mathrm{sCr} \\
\text { elevated }>3 \text { times } \\
\text { or GFR decline }>75 \% \\
\mathrm{sCr} \geq 354 \mu \mathrm{mol} / \mathrm{L} \\
\text { or an acute increase of } \\
\geq 44 \mu \mathrm{mol} / \mathrm{L} \\
\text { Loss: persistent renal } \\
\text { failure }>4 \text { weeks } \\
\text { ESRD: persistent renal failure > } \\
3 \text { months }\end{array}$ & $\begin{array}{l}\text { sCr elevation }>3.0 \text { times } \\
\text { the baseline value } \\
\text { or sCr value } \geq 354 \mu \mathrm{mol} / \mathrm{L} \\
\text { or an increase in acute sCr } \\
\text { values } \geq 44 \mu \mathrm{mol} / \mathrm{L}\end{array}$ & $\begin{array}{l}\mathrm{sCr} \text { elevated } \geq 353.6 \\
\mu \mathrm{mol} / \mathrm{L}(4 \mathrm{mg} / \mathrm{dl}) \text { or elevated } \\
>3.0 \text { times the baseline } \\
\text { value } \\
\text { or starting kidney } \\
\text { replacement therapy or }< \\
18 \text {-year-old patients with a } \\
\text { decrease in eGFR to }<35 \\
\mathrm{ml} / \mathrm{min} / 1.73 \mathrm{~m}^{2}\end{array}$ \\
\hline
\end{tabular}

factors for the nephrotoxicity of NSAIDs have been analyzed, including $\mathrm{CKD}$, old age, cardiomyopathy with impaired cardiac function, diabetes, diuretic and ACEI therapy, vascular disease, hypertension, and fluid deficiency. Selective COX-2 inhibitors have caused relatively few adverse effects on the kidney, including reduced glomerular filtration rate (GFR), elevated serum creatinine ( $\mathrm{SCr}$ ), and hypertension $(28,29)$. Even this conclusion is disputed, as it has been suggested that there is no significant difference in the risk of kidney injury between selective and non-selective COX-2 inhibitors (30), and there are objective case reports of serious kidney injury due to COX-2 inhibitors (66). Additionally, NSAIDS are currently considered to be the second- or third-leading cause of drug-induced acute interstitial nephritis (AIN), with an incubation period of up to 6-12 months $(31,32)$, and although the pathological presentation is relatively mild, with few eosinophil infiltrates and little granuloma formation, it is associated with an increased risk of occurrence with advancing age and is usually considered more likely to progress to chronic kidney disease $(32,33)$. Therefore, the use of NSAIDs, as one of the measures to reduce the pain burden of surgical patients, must be carefully evaluated to balance their benefits and risks. Especially in the surgical population with underlying renal disease, NSAIDs should be avoided and choose alternative analgesics (including opioids)when necessary (Table 3). However, NASIDS may also be considered along with other analgesic therapies after careful assessment of the patient's status (67).

Current findings on the use of ACEIs and ARBs during the perioperative period to induce or exacerbate AKI are inconsistent, and the prevailing view now is that perioperative treatment with ACEIs/ARBs increases the incidence of postoperative AKI by the readily accepted mechanism of intraoperative hypotension and renal artery vasoconstriction leading to renal hypoperfusion, both clearly suggesting that preoperative discontinuation of ACEIs or ARBs is a reasonable strategy (34-36). However, the results of Shah et al. (37) showed that the use of ACEIs/ARBs reduced the absolute risk of AKI by $0.09 \%$ and the absolute risk of all-cause mortality by $0.35 \%$, and this correlation was mainly evident in patients with preoperative CKD. In contrast, a prospective multicenter study of 949 patients undergoing selective non-cardiac surgery for endpoint events showed no association between perioperative ACEI/ARB use and postoperative AKI events, but it is worth noting the apparent selection bias of this study. In addition, the lack of systematic analysis of the complexity of the hemodynamics of the enrolled patients and the exclusion of urine volume as a diagnostic indicator only by a single indicator of blood creatinine level might have interfered with the final results (68). In conclusion, during the perioperative period, especially on the day of surgery, ACEI or ARB drugs should be avoided as much as possible to protect the kidneys while also reducing the risk of severe hypotension during anesthesia. It is also important to note that repeated use of these drugs should be avoided until the patient awakens postoperatively to minimize the risk of hypoperfusion (Table 3).

In a recent study on antibiotic-induced AKI, partial data from the FAERS (FDA Adverse Event Reporting System) were collected, and the odds ratio (OR) of the antibiotic/AKI association was calculated from 2,042,801 reports. The antibiotics ranked as follows by their ORs: colistin aminoglycosides, vancomycin, methotrexate sulfamethoxazole, penicillins, clindamycin, cephalosporins, macrolides, linezolid, carbapenems, metronidazole, tetracyclines, and fluoroquinolones (69). The nephrotoxicity of these antibiotics can be divided into blood concentration-dependent and timedependent. $\beta$-Lactam antibiotics mainly cause time-dependent nephrotoxicity, while neoquinolones and aminoglycosides mainly cause concentration-dependent nephrotoxicity. There are three main mechanisms by which antibiotics cause nephrotoxicity, namely, dose-dependent tubular necrosis, 
TABLE 2 | Analysis of risk factors for perioperative AKI.

\section{Risk factors Details of contents}

Impaired clinical status

Drugs that may impair kidney function

Intravenous (arterial) injection of contrast media

Special surgical interventions

(n)

\section{Anesthesia}

Anemia and the effects of blood transfusion

Anemia

Blood transfusion

ACEl and ARB

Antibiotics

Heart surgery

Narcotic drugs
Age $\geq 56$ years, male, active congestive heart failure, ascites, hypertension, preoperative creatinine $>10^{6} \mathrm{~mol} / \mathrm{L}$, diabetes mellitus (controlled by either oral medication or insulin injections), ventilator dependence, chronic obstructive pulmonary disease, smoking, coagulation disorders, cancer, obesity, and long-term steroid use
Non-steroidal anti-inflammatory drugs

Liver transplantation

Abdominal aortic aneurysm surgery

Pulmonary endarterectomy

Anesthesia method

Malnutrition

Hyperglycemia
Selective COX-2 inhibitors have relatively few adverse effects on the kidney

No significant difference in the risk of kidney injury between COX-2 inhibitors and non-selective COX inhibitors

Perioperative treatment with ACEI/ARB increases the incidence of postoperative AKI

Absolute risk of perioperative AKI reduced with ACEI/ARB

Aminoglycosides can cause renal tubular toxicity

Vancomycin is most likely to produce nephrotoxicity through increased reactive oxygen species and oxidative stress

Fluoroquinolones were graded in order of nephrotoxicity as ciprofloxacin, moxifloxacin and levofloxacin fluoroquinolones can cause AIN

High-dose cephalosporin treatment causes proximal tubular necrosis and renal insufficiency in rats

The prevalence of $\mathrm{Cl}-\mathrm{AKI}$ is $2 \%$ in the general population but increases to $20-40 \%$ in high-risk patients

There was no significant difference in the incidence of AKI between the contrast and control groups

Intra-arterial contrast injection is more nephrotoxic than intravenous use

No significant difference in $\mathrm{AKI}$ incidence with vs. without $\mathrm{PCl}$ in STEMl patients

Higher incidence of AKI after heart valve surgery with increased subsequent dialysis dependence and in-hospital mortality

The incidence of perioperative AKI is high, and the occurrence and progression of AKI affect the short-term and long-term survival of the graft

The operation can increase the risk of perioperative AKI

Severity of postoperative AKI after open repair is independently associated with increased in-hospital mortality in patients with postoperative AKI

The incidence of postoperative AKI is higher in patients with chronic thromboembolic pulmonary hypertension

Intraoperative MAP consistently $<60 \mathrm{mmHg}$ for $20 \mathrm{~min}$ and $<55$ $\mathrm{mmHg}$ for $10 \mathrm{~min}$ increased the incidence of postoperative AKI

Reduced risk of renal failure in patients treated with intraspinal anesthesia compared to general anesthesia

Sevoflurane anesthesia reduces kidney injury in small volume liver transplant rats

Higher incidence of AKI in patients with sevoflurane than in those receiving propofol

Propofol preserves the morphological integrity of the kidney and attenuates AKI in mice undergoing cecum ligation and puncture surgery

Reduced perioperative hemoglobin concentration is strongly associated with the development of postoperative AKI Increased risk of perioperative AKI is directly proportional to the number of red blood cell infusions

Perioperative nutritional status of patients is closely related to the occurrence of AKI

Hyperglycemia is considered one of the independent predictors of increased mortality and worsened prognosis in perioperative patients
NSAIDS can cause drug-induced acute interstitial nephritis (AIN)
$(28,29)$ 
TABLE 3 | Perioperative AKI prevention and management.

\section{Perioperative AKI prevention}

Inclusion of renal risk confirmation in preoperative assessment

Minimize intraoperative renal toxin exposure

Intraoperative management and hemodynamic optimization

Remote ischemic preadaptation

Drug prevention a) Enhance preoperative specialist evaluation and optimize surgical plan

b) Incorporate a multidisciplinary approach to the perioperative care for patients at high risk of $\mathrm{AKI}$

a) Avoid ACEl or ARB drugs in the perioperative period

b) Use NSAIDS with caution in the perioperative period, avoid in certain special cases, or choose alternative analgesics

c) Use the lowest volume of contrast agent that achieves the examination while considering first non-ionic isotonic contrast agent or hypotonic contrast agent

d) The specific benefits of perioperative hydration are controversial, but studies continue to support this prophylactic measure

e) The effectiveness of acetylcysteine and pentoxifylline is still controversy

f) Statins may help to reduce the incidence of $\mathrm{Cl}-\mathrm{AKI}$, but their mechanism of action has not been fully determined

a) The routine use of hydroxyethyl starch in surgery is not currently recommended for patients with $\mathrm{AKI}$ or co-operative risk factors

b) Balanced salt solution is recommended to maintain adequate renal perfusion

c) Guaranteed MAP > 60-65 mmHg (>75 $\mathrm{mmHg}$ in chronic hypertensive patients)

a) Remote ischemic preadaptation reduced the incidence of major adverse renal events in patients undergoing high-risk cardiac surgery

b) Remote ischemic preadaptation may promote renal recovery in patients with perioperative AKI

c) Statins have been shown to reduce the incidence of perioperative AKI

\section{Perioperative AKI management}

Early diagnosis

Discovery of AKI complications

Administration of vasopressors

Use of other drugs

Nutritional support

Renal replacement therapy
Discovery of AKI etiology

Use of biomarkers to supplement serum creatinine and urine output for the early identification of $\mathrm{AKI}$ in high-risk patients
Correction of disorders of acid-base balance, water and electrolyte imbalance, etc.

Maintenance of adequate perfusion pressure (mean arterial pressure $>65 \mathrm{mmHg}$, systolic pressure $>100 \mathrm{mmHg}$ )

Dexmedetomidine: currently considered the most promising effect (in order to ensure the safe use of dexmedetomidine, patients must be carefully selected in clinical practice and the appropriate dose must be determined)

Furosemide: guidelines recommend only for correction of fluid imbalances and electrolyte abnormalities in patients with AKI Sodium bicarbonate, dopamine, vasodilators, and natriuretic peptides: not recommended by guidelines at this time

Patients with $\mathrm{AKI}$ at any stage: ensure an energy intake of $20-30 \mathrm{kcal} / \mathrm{kg} /$ day CRRT treatment: provide up to $1.7 \mathrm{~g} / \mathrm{kg} /$ day of amino acids

Non-dialysis patients: provide $0.8-1.0 \mathrm{~g} / \mathrm{kg} / \mathrm{day}$ of amino acids

Correction of internal environmental disturbances and reduction of excessive fluid load allergic tubulointerstitial nephritis, and tubular crystalline formation. Excessive concentrations of aminoglycosides in renal tubules cause tubular toxicity by accumulating in lysosomes, Golgi apparatus, and endoplasmic reticulum and binding to membrane phospholipids, altering their turnover and metabolism, leading to phospholipidosis (38). The most likely mechanism of vancomycin nephrotoxicity is attributed, at least in part, to increased reactive oxygen species and oxidative stress, and the risk factors are thought to be high drug concentration $(>20 \mathrm{mg} / \mathrm{L})$ or high doses $(>4 \mathrm{~g} / \mathrm{h})$, concomitant use of other nephrotoxic drugs, prolonged drug treatment $(\geq 7 \mathrm{~d}$, and intensive care status (39). Current cases of AIN caused by quinolones are mainly associated with older fluoroquinolones, fluoroquinolones were graded in order of nephrotoxicity as ciprofloxacin, moxifloxacin and levofloxacin, with relative risks of 2.76, 2.09, and 1.69, respectively (40). In 2014, Muriithi et al. (41) reported a series of kidney biopsy case, it was again confirmed that fluoroquinolones can cause AIN, while follow-up studies also found that early steroid treatment or hydration therapy improved recovery of renal function in patients with drug-induced AIN (70, 71). Similarly, Bird et al. (40) found that the relative risk of AKI caused by treatment with fluoroquinolones was 2.18. However, considering the risk of death due to serious infections, the current study findings do 
not negate the use of fluoroquinolones, and mainly remind the importance of prescribing in clinical work.

There are more reports related to cephalosporins causing AKI in this century, and in a transcriptomic study analysis by Rokushima et al. (42) on the nephrotoxicity of cephalosporin antibiotics, it was observed that high-dose cephalosporin treatment caused proximal tubular necrosis and renal insufficiency in rats. Mac et al. (72) first reported a case of cefepime causing AIN in 2015. Although cefepime is considered a safe antibiotic from a nephrotoxicity point of view and renal-related adverse reactions are rare, clinicians still need to be aware of the nephrotoxicity associated with the use of cefepime, especially in patients on long-term treatment, who should be monitored closely for renal function parameters. However, there is a lack of large epidemiological findings of cephalosporins alone causing AKI as well as specific controlled studies, a lack of intermediate to high-level evidence to support the association between the two, and the only relevant studies are mostly case reports or adverse renal outcomes after combination with other drugs (69). Therefore, it is still one of the most important drugs for the prevention or treatment of infectious diseases in clinical workup, especially in the perioperative period, and it is believed that more research evidence will be available in the future to support or limit it, as well as to provide more guidance in prescribing doses and drug combinations.

\section{Contrast Injection}

Contrast-induced AKI (CI-AKI) is defined as an increase in BUN and $\mathrm{sCr}$ or a decrease in eGFR occurring usually $24-72 \mathrm{~h}$ after drug administration (73) (Table 2), but its specific definition is not uniform, which hinders cross-study comparisons. It is now believed that the possible mechanisms of CI-AKI include the following: first, renal hemodynamic changes that cause renal medullary hypoxia; second, direct toxic injury effects of contrast agents on renal endothelial cells and proximal tubular cells (74-76); and third, changes in renal microcirculation due to the release of certain neurohumoral mediators or increased blood viscosity (77). In most patients, CI-AKI is likely to be transient and reversible, although some studies have reported its association with increased long-term patient mortality (7880 ). The prevalence of CI-AKI is $2 \%$ in the general population but increases to $20-40 \%$ in high-risk patients, such as those with diabetes, congestive heart failure, or chronic kidney disease and who are elderly (43), but most studies lack a credible control group or strict adjustment for AKI covariates, leading to infirm conclusions. For example, one study concluded that the incidence of CI-AKI significantly increased with decreasing baseline eGFR values, yet there was no significant difference in the incidence of AKI between the contrast and control groups in any eGFR subgroup, even among patients with eGFR $<30 \mathrm{ml} / \mathrm{min} / 1.73 \mathrm{~m}^{2}$ (44). Similarly, a clinical evaluation by Wilhelm-Leen et al. (81) of 5.9 million enrolled patients showed that the incidence of AKI was even lower in patients receiving contrast than in controls after adjustment for risk factors.

In recent years, along with the increasing number of patients with vascular lesions receiving endovascular treatment, perioperative contrast nephropathy has been gaining attention. The site of contrast injection may have an impact on the incidence of CI-AKI, and some studies have shown a significantly higher incidence of AKI after coronary angiography than intravenous injection (45), the reason for which may be related to its initial concentration in the renal vascular system, as aortography has demonstrated a greater risk of AKI if the contrast is injected directly into the proximal renal artery. However, the conclusion that arterial contrast injection causes AKI is equally questionable, as demonstrated in the Caspi et al. (46) study. Among STEMI patients, there is no significant difference in the incidence of AKI with or without PCI intervention, and independent predictors of AKI in the PCI treatment cohort included age $\geq 70$ years, insulin-treated diabetes, diuretic therapy, eGFR reduction, cardiac pump failure, and reduced left ventricular ejection fraction, independent of contrast dose. Therefore, it must be noted that CI-AKI is still a controversial topic, and no study has been able to explain it thoroughly, which even questions the rationality of CI-AKI, so it is still an exclusionary diagnosis according to the definition of CI-AKI and needs a more rigorous follow-up study that fully controls for other risk factors or confounders.

Nevertheless, currently in clinical workup, great caution is still needed in the perioperative injection of contrast agents into patients assessed preoperatively to be at risk for renal damage. There are several ways to reduce this risk, including the use of the lowest volume of contrast agent that achieves the examination objectives while first considering non-ionic isotonic contrast or hypotonic contrast (Table 3). In addition, although there is controversy about the specific benefits of perioperative hydration, and there are no firm conclusions about the ideal material, dose, and rate of hydration, many studies still support this prophylactic measure, especially in cardiovascular surgery (Table 3). In addition to. The assessment of cardiac function, $0.9 \%$ sodium chloride or isotonic sodium bicarbonate solution is given perioperatively to ensure adequate intravascular volume and to minimize the risk and extent of contrast-induced renal injury $(82,83)$. This same prophylactic strategy is clearly recommended in the European Society of Cardiology (ESC) guidelines on myocardial revascularization, with specific guidelines recommending the administration of intravenous saline $12 \mathrm{~h}$ before and $24 \mathrm{~h}$ after the administration of contrast media, with intravenous saline at a rate of 1-1.5 $\mathrm{ml} / \mathrm{kg} / \mathrm{h}$, especially in patients with GFR $<40 \mathrm{ml} / \mathrm{min} / 1.73 \mathrm{~m}^{2}$ (84). In terms of drug prevention, there is still controversy regarding the effectiveness of acetylcysteine, which can be supported only partially by evidence (85-87). Similarly, statins may help to reduce the incidence of CI-AKI, but their mechanism of action has not been fully understood (8891). There are also some reports on pentoxifylline, but most of them focus on animal studies $(92,93)$, in clinical studies, more emphasis has been placed on its combined effect with drugs such as berberine hydrochloride for druginduced AKI, and for contrast-associated AKI, although it may reduce creatinine elevation in the short term, its preventive effect cannot be fully confirmed based on the available evidence $(94,95)$. 


\section{Special Surgical Interventions}

Surgery itself is a risk factor for AKI, in particular, some specific types of surgery are associated with an increased risk of kidney injury. A retrospective study of patients undergoing heart valve surgery found a $6.1 \%$ incidence of postoperative AKI, new dialysis dependence in $3.1 \%$ of AKI patients, death during hospitalization in $48.9 \%$, discharge with recovery of renal function in $42.2 \%$, and permanent dialysis dependence in $8.8 \%$ (47) (Table 2). The reasons were the use of preoperative contrast agents, decreased perfusion pressure and reduced pulsatile blood flow during bypass surgery, decreased mean arterial pressure during extracorporeal circulation, exposure to extracorporeal circulation triggering a contact systemic inflammatory response, low temperature or mechanical destruction of red blood cells by extracorporeal circulation, and formation of an obstructive tubular pattern by hemoglobin $(96,97)$. However, there is no consensus on whether extracorporeal circulation necessarily constitutes a cause of the high incidence of AKI in cardiovascular surgery, previous findings suggest that cardiopulmonary bypass with extracorporeal circulation increases the incidence of AKI and other renal diseases $(98,99)$, the results of the study by Reents et al. (100) found that non-extracorporeal coronary artery bypass grafting was not associated with a reduction in the incidence or severity of AKI.

One study reported that the incidence of perioperative AKI decreased to $11-68 \%$ after the introduction of an end-stage liver disease model scoring system as a basis for liver transplantation matching (101). Hepatic ischemia-reperfusion injury may act as the main pathogenesis of AKI after liver transplantation by driving the systemic inflammatory response. In a study by Hilmi et al. (48), analysis of clinical and laboratory data from 424 liver transplant recipients found that at $72 \mathrm{~h}$ posttransplantation, AKI occurred in 221 patients (52\%) and concluded that female sex, weight $\geq 100 \mathrm{~kg}$, high Child-Pugh score, and diabetes mellitus were significantly associated with the occurrence of AKI within $72 \mathrm{~h}$. Additionally, the occurrence and progression of AKI within $72 \mathrm{~h}$ after transplantation affected the short- and long-term survival of the graft (48) (Table 2).

Abdominal aortic aneurysm surgery is another surgical operation that has been clearly reported to exacerbate the risk of perioperative AKI. In a study conducted in 2015, 149 patients undergoing open repair of abdominal aortic aneurysms were enrolled and analyzed for postoperative data, $18.8 \%$ of whom developed AKI, and the next $33 \pm 11$ months of follow-up investigation revealed that, although no patients required dialysis treatment, the occurrence of AKI was strongly associated with high mortality and high incidence of cardiovascular disease (49) (Table 2). Whereas, the kind of procedure also affects the incidence of postoperative AKI, the severity of AKI after open repair is independently associated with increased in-hospital mortality in patients with postoperative AKI (Table 2), and major risks include aortic clamping, perioperative hypotension, atherosclerotic embolism, and impaired renal blood flow due to exposure to blood products (50).

Zhang et al. (51) published the first report on a complication study of 123 patients diagnosed with chronic thromboembolic pulmonary hypertension (CTEPH) who underwent pulmonary endarterectomy (PEA). Their data suggested that the incidence of postoperative AKI was $45 \%$ (Table 2); that preoperative platelet count, hemoglobin concentration, and duration of deep hypothermic circulation stagnation were independent factors associated with AKI; and that renal protection strategies should be prioritized in the perioperative management of such procedures (51). However, some unknown confounding factors (such as perioperative nephrotoxic drug use) were not explicitly excluded in this study, and there are not enough other relevant studies due to the low incidence of $\mathrm{CTEPH}$, resulting in some limitations of the findings.

\section{Anesthesia}

Intraoperative anesthesia can affect renal function in different ways and increase the risk of perioperative AKI, mainly due to the choice of anesthesia method and drug (Table 2). The study by Sun et al. (52) suggested that intraoperative anesthesiainduced hypotension was closely related to the occurrence of postoperative AKI, and intraoperative MAP consistently $<60$ $\mathrm{mmHg}$ for $20 \mathrm{~min}$ and $<55 \mathrm{mmHg}$ for $10 \mathrm{~min}$ increased the incidence of postoperative AKI. The results of a meta-analysis by Rodgers et al. (53) in 2000 showed that compared with general anesthesia, patients treated with intraspinal anesthesia had a reduced risk of renal failure. However, some studies have also indicated a similar incidence of AKI with epidural anesthesia combined with general anesthesia compared to general anesthesia alone (102), so the specific effects of intraspinal anesthesia on renal function still need to be confirmed by more studies.

In animal studies, sevoflurane anesthesia was shown to reduce renal injury in small-volume liver transplant rats by significantly lowering the 24 -h sCr after reperfusion and NGAL concentrations after $2 \mathrm{~h}$ reperfusion in rats with sevoflurane (54). However, in human patients, a retrospective study suggested that the incidence of AKI was higher in patients receiving sevoflurane than in those receiving propofol, suggesting that sevoflurane anesthesia may be associated with the development of postoperative AKI (55). In contrast, another domestic animal study suggested that propofol improved survival after cecum ligation and puncture surgery (CLP) in mice, preserved the morphological integrity of the kidney in mice undergoing CLP, and lowered the occurrence of AKI (56). There is a lack of human studies on perioperative anesthetics causing AKI, and more highlevel evidence is needed to rule out or confirm this view.

\section{Anemia and blood transfusion}

Walsh et al. (57) concluded that decreased perioperative hemoglobin concentration is strongly associated with the development of postoperative AKI (Table 2). Another study reached the same conclusion, as the postoperative decrease in hemoglobin from baseline was positively associated with the decrease in eGFR, and the OR value was proportional to the degree of hemoglobin decrease (103). The causes are as follows: anemia decreases renal oxygen delivery, especially to the renal medulla, where normal oxygen partial pressure is low; during surgery, the kidneys are more prone to underperfusion, and the important antioxidant function of red blood cells is reduced, 
aggravating intraoperative renal oxidative stress; and anemia increases the chances of transfusion and aggravates AKI due to transfusion (58).

Previous studies concluded that the increased risk of perioperative AKI is directly proportional to the amount of red blood cell transfusion, and this correlation is particularly evident in anemic patients (Table 2). This finding has been widely confirmed in cardiac surgery, where a variety of blood-sparing measures are recommended (58-60). The causes are that red blood cells become less deformable during storage, while ATP and 2-3DPG are depleted and lose their abilities to produce NO, enhance vascular endothelial cell adhesion, release procoagulant phospholipids and accumulate proinflammatory molecules, free iron, and hemoglobin; stored red blood cells may impair tissue oxygen delivery, promote an inflammatory state, exacerbate tissue oxidative stress, and activate leukocyte and coagulation cascade reactions. Possible mechanisms why anemic patients are more susceptible to transfusion-associated AKI include the following: first, anemic patients are usually more anemic during cardiac surgery, resulting in less oxygen delivery and making the kidneys more susceptible to hypoxic injury; second, some anemic patients will have subclinical nephropathy characterized by increased renal tubular oxygen consumption and oxidative stress, making the kidneys susceptible to acute or chronic damage (104); third, anemic patients have abnormal iron metabolism and a weaker ability to cope with an increased iron load due to multiple transfusions, triggering iron-mediated oxidative kidney injury (105). However, transfusions, like anemia, lack the results of large randomized controlled trial or meta-analyses, and the only conclusions available are mostly complication studies of specific types of surgery, which cannot adequately demonstrate their relationship with AkI in non-cardiac surgery. In addition, it is worth mentioning that in a meta-analysis published in recent years, findings suggest that administering EPO before anesthesia is emerging as an important factor for efficacy. Erythropoietin may have a role in preventing cardiac surgery associated acute kidney injury (CSA-AKI), however, additional high-quality prospective studies are warranted, particularly aimed at the timing and size of the dose (106).

\section{Malnutrition}

Malnutrition is also an important risk factor that increases the incidence of perioperative AKI (Table 2). Nutrition is the basis of cellular and organ function, and malnutrition may worsen the severity of disease by significantly changing renal hemodynamics and renal concentrating capacity (107). Malnutrition in children and adults decreases the glomerular filtration rate, and experimental models show that the reninangiotensin system, renal prostaglandin secretion and overall renal function are altered in malnourished states, although the exact mechanisms remain incompletely understood $(108,109)$. This malnutrition can be manifested in several ways, including in the concentrations of albumin, vitamins, electrolytes, minerals, and trace elements. Several studies have confirmed the correlation between low or deficient nutrients and the development of AKI in patients with infectious diseases, cancer, surgery and other causes of critical illness, showing that malnutrition is an independent risk factor and suggesting that following AKI guidelines to prevent and treat AKI by providing nutritional support, especially to children and elderly patients (110-114). In addition, similar views have been proposed in several studies on risk factors assessment for surgery-related AKI, as well as studies on the correlation between preoperative prognostic nutritional index and AKI, it was suggested that perioperative nutritional status of patients is closely related to the occurrence of AKI (61-65).

Nutritional support is also a priority in the follow-up treatment of AKI patients (Table 3). According to the KIDGO guidelines for the nutritional support of AKI patients, an energy intake of $20-30 \mathrm{kcal} / \mathrm{kg} / \mathrm{day}$, mainly carbohydrates and fats, should be ensured regardless of the stage of the disease. In the case of CRRT, considering the normal protein metabolic rate and filtration losses, a maximum of $1.7 \mathrm{~g} / \mathrm{kg} /$ day of amino acids needs to be actively provided to compensate for these losses, while in non-dialysis patients, this value must be $0.8-1.0 \mathrm{~g} / \mathrm{kg} / \mathrm{day}$, and it is recommended to provide nutrition mostly through the enteral route (5).

\section{Hyperglycemia}

Hyperglycemia is considered one of the independent predictors of increased mortality and worsened prognosis in perioperative patients and should be optimized in perioperative patients. The KDIGO criteria recommend maintaining blood glucose concentrations between 110 and $149 \mathrm{mg} / \mathrm{dl}$ in critically ill patients to minimize all-cause mortality, surgical complications and increased risk of AKI due to hyperglycemia in the perioperative period (5) (Table 2).

\section{PREVENTION OF PERIOPERATIVE AKI}

\section{Preoperative Assessment of Renal Risk}

As part of this process, it is recommended to enrich the details of the assessment, include strictly kidney-related risk factors, integrate and stratify them scientifically, classify the kidney function in a timely manner, identify possible underlying kidney diseases, strengthen contact with anesthesia and kidney specialist physicians, receive professional advice, and provide clinicians with more scientific reference for preoperative guidance, while communicating to the patient team the likelihood and degree of risk of perioperative AKI and optimizing the surgical plan. In addition, it is also possible to incorporate a multidisciplinary approach to the perioperative care for patients at high risk of AKI. However, there are few reports that have taken such an approach, and no specific benefits can be determined (Table 3).

\section{Intraoperative Management and Hemodynamic Optimization}

Perioperative renal protection focuses on maintaining adequate renal perfusion, which is largely dependent on adequate intravascular volume and mean arterial pressure, but fluid supplementation alone may not overcome the effects of hypotension during anesthesia in some patients and may lead to postoperative complications. According to the conclusions 
of a recent meta-analysis, optimization of intravascular volume and cardiac output may have a positive impact on perioperative renal function in high-risk patients (definition of high risk was based on need of emergent surgery, and/or elective major surgery in patients with risk criteria defined by perioperative scoring system, ASA physical status classification, age $>60$ years, and preoperative morbidity), at three preoperative, intraoperative or postoperative time points with fluid combination of supplementation and cardiac agents reduces the incidence of renal insufficiency and significantly reduces mortality (115), but this procedure requires careful monitoring of volume status to avoid volume overload, and in terms of specific fluid selection, balanced salt solutions are more recommended to avoid the risk that AKI that is exacerbated by perioperative saline overinfusion will lead to hyperchloremia (116). While the use of colloidal solutions is controversial, and the routine use of hydroxyethyl starch in surgery is not currently recommended for patients with AKI or co-operative risk factors (117-119). As for the threshold of mean arterial pressure, several studies have confirmed that even short-term hypotensive states can damage the kidneys, so ensuring MAP $>60-65 \mathrm{mmHg}$ ( $>75 \mathrm{mmHg}$ in patients with chronic hypertension) is recommended to prevent AKI $(52,120)$ (Table 3), and a more individualized approach to intraoperative arterial pressure management should also be taken in this process.

\section{Remote Ischemic Preadaptation}

Remote ischemic preadaptation is an experimental approach to provide organ protection with short cycles of harmless ischemia and reperfusion applied to the arm or leg, a pathway thought to drive the stabilization of transcription factors such as hypoxiainducible factor (HIF1a or HIF2a), a transcriptional program that mediates the release of soluble mediators (IL-10, adenosine, circulating nucleotidases) from ischemic muscle into the body circulation, thereby providing protection to remote organs (e.g., the heart or kidney) (121) (Table 3). Zarbock et al. (122) conducted a large, multicenter, randomized, double-blind clinical trial in 2015, which suggested that remote ischemic preadaptation significantly reduced the incidence of major adverse renal events at 90 days in patients undergoing high-risk cardiac surgery compared to controls, while suggesting that remote ischemic preadaptation may promote renal recovery in patients with perioperative AKI. Similarly, the results of two recent metaanalyses confirm this view $(123,124)$. However, like others, this conclusion still faces contrary opinions. Hausenloy et al. (125) included a controlled study of a total of 1,612 patients undergoing cardiac surgery in 30 centers with an observation period of 12 months and showed that the difference in the incidence of major endpoint events between patients in the remote ischemic preadaptation and control groups was not statistically significant, including the incidence of AKI, duration of ICU care, and length of hospital stay. More recently, data from a meta-analysis on 3,660 patients in 43 RCTs show a similar conclusion that remote ischemic preadaptation reduced cardiovascular events after non-cardiac surgery, but had no significant advantage for the incidence of AKI and all-cause mortality (126). Therefore, further studies are still needed to collect relevant evidence and validate the specific effect of remote ischemic preadaptation in perioperative AKI prevention.

\section{Drug Prevention}

Statins have potential anti-inflammatory and antioxidant effects and have been shown to reduce the incidence of perioperative AKI, the risk of RRT, and 14-day mortality in a clinical study enrolling 200,000 patients (127) (Table 3), but there are no consistent findings in several studies related to cardiac surgery $(128,129)$, and in recent years the preventive effects of statins on contrast nephropathy (CIN-AKI) have been supported by the results of several studies (91), so the general recommendation on statins for AKI is currently uncertain because of the lack of evidence from prospective trials.

\section{PERIOPERATIVE AKI MANAGEMENT}

\section{Early Diagnosis}

A detailed bedside examination is performed to look for all possible etiologies that may precipitate perioperative AKI (Table 3), mainly from the prerenal, renal and postrenal perspectives and to rule out causes such as urinary tract obstruction as quickly as possible with the help of imaging. Blood creatinine values and urine volume are also closely monitored to keep track of changes dynamically, to quickly assess the patient's volume status, and to check whether the patient has sufficient vascular volume reserve or possible overload. In addition, we suggest the use of biomarkers to supplement serum creatinine and urine output for the early identification of AKI in highrisk patients (Table 3), especially target molecules that have been approved for use in some jurisdictions, such as NGAL, L-FABP, TIMP-2, and IGFBP7. However, this is not easy. On the one hand, the source of some biomarkers is not clear, and it is also difficult to determine the cut-off threshold of each marker for different races. On the other hand, the complexity of perioperative patients also interferes with the diagnostic performance of markers.

\section{Discovery of AKI Complications}

Timely detection and management of various complications of perioperative AKI (Table 3), including disorders of acidbase balance, water and electrolyte imbalance (hyperkalemia, volume overload, acidosis, etc.), and consideration of reduced fluid infusion in some patients are needed to maintain in/out balance, but special attention needs to be paid to the estimation and calculation of hidden fluid losses during this period.

\section{Administration of Vasopressors}

The protection of renal function depends to a large extent on the maintenance of renal perfusion, and the maximum benefit of treatment after renal damage in high-risk surgical patients can be achieved by maintaining hemodynamic stability. In cases where fluid resuscitation is ineffective or can only be maintained briefly, vasopressors can be administered to maintain adequate perfusion pressure (mean arterial pressure 
$>65 \mathrm{mmHg}$ and systolic pressure $>100 \mathrm{mmHg}(130,131)$ (Table 3). In addition, in patients with moderate to severe ventricular insufficiency, concurrent administration of positive inotropes, and fluid therapy may be attempted. However, in patients with complex conditions, the best approach is to provide a highly dependent environment that allows for optimal monitoring.

\section{Use of Other Drugs}

Due to the heterogeneity of AKI, identifying a single therapy that will benefit all patients is challenging, and numerous drugs are being studied in clinical trials, but the overall results remain less than promising (Table 3 ). Dexmedetomidine, a highly selective $\alpha$-blocker, has been shown to have renoprotective effects in several cardiac surgery studies and is thought to act mainly by reducing norepinephrine release, improving hemodynamic stability, and maintaining myocardial oxygen supply balance, thereby significantly reducing the incidence of AKI, especially in patients with normal or mildly impaired preoperative renal function $(132,133)$. The most recent meta-analysis in 2021 confirmed that dexmedetomidine had a renoprotective effects after surgery, with NGAL levels reduced and creatinine clearance significantly increased in patients treated with it (134). Unfortunately, there are no clear recommendations on treatment strategies, including in the KIDGO guidelines. Therefore, we suggest that in order to ensure the safe use of dexmedetomidine, patients must be carefully selected in clinical practice and the appropriate dose must be determined.

Furosemide is a widely used diuretic in clinical practice, and data from some studies suggest that it may improve the balance of oxygen supply and demand in the renal medulla by inhibiting $\mathrm{Na}-\mathrm{K}-\mathrm{Cl} 2$ cotransporter activity, increasing prostaglandin production and blood flow, and preventing tubular obstruction due to endothelial cell shedding. However, clinical studies based on this hypothesis have not yielded positive results and have concluded that it should not be used for the routine treatment of AKI $(135,136)$. Even so, the KIDGO guidelines, mainly the Japanese AKI guidelines and the NICE (National Institute for Health and Clinical Excellence) guidelines, still recommend furosemide for the correction of fluid imbalances and electrolyte abnormalities in patients with AKI (Table 3).

Other drugs, including sodium bicarbonate, dopamine, vasodilators, and natriuretic peptides, have been clearly demonstrated in multiple studies to have no AKI prevention or treatment benefit and are not included in guideline recommendations. Later studies may provide evidence to the contrary, but at least at this stage, dexmedetomidine has the most promising effect (Table 3).

\section{Renal Replacement Therapy}

There is no positive evidence that renal replacement therapy has a positive effect on the development of perioperative AKI, but replacement therapy itself can correct internal environmental disturbances and reduce excessive fluid load and can be used in a timely manner at the onset of AKI to reduce symptoms while buying valuable time for comprehensive treatment in other areas (Table 3). In particular, continuous renal replacement therapy is recommended for patients with complex conditions and hemodynamic instability. In addition, to decide on the use of anticoagulants, detailed information about the patient's bleeding history and major surgery history must be obtained to fully determine the patient's coagulation function, and heparin can be avoided or replaced with topical citrate or argatroban anticoagulation to avoid the risk of severe bleeding when conditions permit (137). The ideal mode of renal replacement therapy, its timing and the duration of initiation of therapy are still under debate. A randomized controlled study of 620 patients conducted by Gaudry et al. (138) in 2016 suggested no significant difference in mortality between patients in the early and delayed strategy groups, with patients in the early strategy group mostly starting therapy within $6 \mathrm{~h}$. In contrast, other clinical studies have drawn different conclusions, the representative report being a randomized controlled study of 231 patients conducted by Zarbock et al. (139) in 2019, which found that the early strategy significantly reduced mortality at $90 \mathrm{~d}$ compared to the delayed strategy.

\section{CONCLUDING REMARKS}

The pathophysiologic mechanisms by which perioperative AKI occurs are complex and varied, but the outcomes all increase the risk of patient death, and the effects of even mild AKI are severe, being correlated with a negative prognosis and ongoing increased mortality. Most cases of AKI occurring in the perioperative period are associated with relative renal hypoperfusion and/or renal damage by nephrotoxins and are less associated with primary renal disease. The likelihood of serious, long-term, progressive consequences can be reduced and the perioperative prognosis improved by following reasonable strategies for early avoidance of perioperative AKI risk factors and enhanced perioperative patient management, as well as a rapid response to and early management of AKI when it occurs.

\section{AUTHOR CONTRIBUTIONS}

All authors listed have made a substantial, direct, and intellectual contribution to the work and approved it for publication.

\section{FUNDING}

The work was supported by the Science and Technology Project of Beijing, China (Z191100006619001), and the Chinese National Natural Science Foundation (No. 81670694).

\section{ACKNOWLEDGMENTS}

We would gratefully thank Technologist Lingling $\mathrm{Wu}$ of the Nephrology Laboratory for her guidance on the submission process. 


\section{REFERENCES}

1. Lewington AJP, Cerdá J, Mehta RL. Raising awareness of acute kidney injury: a global perspective of a silent killer. Kidney Int. (2013) 84:45767. doi: 10.1038/ki.2013.153

2. Eckardt KU, Coresh J, Devuyst O, Johnson R, Köttgen A, Levey AS, et al. Evolving importance of kidney disease: from subspecialty to global health burden. Lancet. (2013) 382:158-69. doi: 10.1016/S0140-6736(13) 60439-0

3. Lameire NH, Bagga A, Cruz D, Maeseneer JD, Endre Z, Kellum JA, et al. Acute kidney injury: an increasing global concern. Lancet. (2013) 382:1709. doi: 10.1016/S0140-6736(13)60647-9

4. Kellum JA, Levin N, Bouman C, Lameire N. Developing a consensus classification system for acute renal failure. Curr Opin Crit Care. (2002) 8:509-14. doi: 10.1097/00075198-200212000-00005

5. Kellum JA, Lameire N, Kdigo Aki Guideline Work Group. Diagnosis, evaluation, and management of acute kidney injury: a KDIGO summary (Part 1). Crit Care. (2013) 17:204. doi: 10.1186/cc11454

6. Hahn RG. Volume kinetics for infusion fluids. Anesthesiology. (2010) 113:470-81. doi: 10.1097/ALN.0b013e3181dcd88f

7. Matot I, Paskaleva R, Eid L, Cohen K, Khalaileh A, Elazary A, et al. Effect of the volume of fluids administered on intraoperative oliguria in laparoscopic bariatric surgery: a randomized controlled trial. Arch Surg. (2012) 147:22834. doi: 10.1001/archsurg.2011.308

8. Bellomo R, Kellum JA, Ronco C. Acute kidney injury. Lancet. (2012) 380:756-66. doi: 10.1016/S0140-6736(11)61454-2

9. Schrezenmeier EV, Barasch J, Budde K, Westhoff T, Schmidt-Ott KM. Biomarkers in acute kidney injury - pathophysiological basis and clinical performance. Acta Physiol. (2017) 219:554-72. doi: 10.1111/apha.12764

10. Teo SH, Endre ZH. Biomarkers in acute kidney injury (AKI). Best Pract Res Clin Anaesthesiol. (2017) 31:331-44. doi: 10.1016/j.bpa.2017.10.003

11. Pickering JW, Endre ZH. Bench to bedside: the next steps for biomarkers in acute kidney injury. Am J Physiol Renal Physiol. (2016) 311:F71721. doi: 10.1152/ajprenal.00268.2016

12. Tanase DM, Gosav EM, Radu S, Costea CF, Ciocoiu M, Carauleanu A, et al. the predictive role of the biomarker Kidney Molecule-1 (KIM-1) in Acute Kidney Injury (AKI) cisplatin-induced nephrotoxicity. Int J Mol Sci. (2019) 20:5238. Published 2019 Oct 22. doi: 10.3390/ijms20205238

13. Lin X, Yuan J, Zhao Y, Zha Y. Urine interleukin-18 in prediction of acute kidney injury: a systemic review and meta-analysis. J Nephrol. (2015) 28:716. doi: 10.1007/s40620-014-0113-9

14. Sun T, Qu S, Huang T, Ping Y, Lin QY, Cao Y, et al. Rapid and sensitive detection of L-FABP for prediction and diagnosis of acute kidney injury in critically ill patients by chemiluminescent immunoassay. J Clin Lab Anal. (2021) 35:e24051. doi: 10.1002/jcla.24051

15. Vakili M, Fahimi D, Esfahani ST, Sharifzadeh M, Moghtaderi M. Comparative analysis between urinary calprotectin and serum creatinine for early detection of intrinsic acute kidney injury. Indian J Nephrol. (2021) 31:353-357. doi: 10.4103/ijn.IJN_83_20

16. Wang $\mathrm{R}, \mathrm{Hu} \mathrm{H}, \mathrm{Hu} \mathrm{S}$, $\mathrm{He} \mathrm{H}$, Shui $\mathrm{H}$. $\beta 2$-microglobulin is an independent indicator of acute kidney injury and outcomes in patients with intracerebral hemorrhage. Medicine. (2020) 99:e19212. doi: 10.1097/MD.0000000000019212

17. Zankar S, Trentin-Sonoda M, Viñas JL, Rodriguez RA, Bailey A, Allan $\mathrm{D}$, et al. Therapeutic effects of micro-RNAs in preclinical studies of acute kidney injury: a systematic review and meta-analysis. Sci Rep. (2021) 11:9100. doi: 10.1038/s41598-021-88746-y

18. Prowle JR, Bellomo R. Sepsis-associated acute kidney injury: macrohemodynamic and microhemodynamic alterations in the renal circulation. Semin Nephrol. (2015) 35:6474. doi: 10.1016/j.semnephrol.2015.01.007

19. Grams ME, Sang Y, Coresh J, Ballew S, Matsushita K, Molnar MZ, et al. Acute kidney injury after major surgery: a retrospective analysis of veterans health administration data. Am J Kidney Dis. (2016) 67:87280. doi: 10.1053/j.ajkd.2015.07.022

20. Meersch M, Schmidt C, Zarbock A. Perioperative acute kidney injury: an under-recognized problem. Anesth Analg. (2017) 125:1223-32. doi: 10.1213/ANE.0000000000002369
21. Djordjević A, Šušak S, Velicki L, Antonič M. Acute kidney injury after open-heart surgery procedURES. Acta Clin Croat. (2021) 60:1206. doi: 10.20471/acc.2021.60.01.17

22. Long TE, Helgason D, Helgadottir S, Palsson R, Gudbjartsson T, Sigurdsson GH, et al. Acute kidney injury after abdominal surgery: incidence, risk factors, and outcome. Anesth Analg. (2016) 122:191220. doi: 10.1213/ANE.0000000000001323

23. Shi N, Liu K, Fan Y, Yang LL, Zhang S, Li X, et al. The association between obesity and risk of acute kidney injury after cardiac surgery. Front Endocrinol. (2020) 11:534294. doi: 10.3389/fendo.2020.534294

24. Madsen NL, Goldstein SL, Frøslev T, Christiansen CF, Olsen M. Cardiac surgery in patients with congenital heart disease is associated with acute kidney injury and the risk of chronic kidney disease. Kidney Int. (2017) 92:751-6. doi: 10.1016/j.kint.2017.02.021

25. Kheterpal S, Tremper KK, Heung M, Rosenberg AL, Englesbe M, Shanks $\mathrm{AM}$, et al. Development and validation of an acute kidney injury risk index for patients undergoing general surgery: results from a national data set. Anesthesiology. (2009) 110:505-15. doi: 10.1097/ALN.0b013e3181979440

26. Kim M, Brady JE, Li G. Variations in the risk of acute kidney injury across intraabdominal surgery procedures. Anesth Analg. (2014) 119:112132. doi: 10.1213/ANE.0000000000000425

27. Weingarten TN, Gurrieri C, McCaffrey JM, Ricter SJ, Hilgeman ML, Schroeder DR, et al. Acute kidney injury following bariatric surgery. Obesity Surg. (2013) 23:64-70. doi: 10.1007/s11695-012-0766-1

28. Chou CI, Shih CJ, Chen YT, Ou SM, Yang CY, Kuo SC, et al. Adverse effects of oral nonselective and cyclooxygenase-2-selective NSAIDs on hospitalization for acute kidney injury: a nested case-control cohort study. Medicine. (2016) 95:e2645. doi: 10.1097/MD.0000000000002645

29. Lafrance JP, Miller DR. Selective and non-selective non-steroidal antiinflammatory drugs and the risk of acute kidney injury. Pharmacoepidemiol Drug Saf. (2009) 18:923-31. doi: 10.1002/pds.1798

30. Swan SK, Rudy DW, Lasseter KC, Ryan CF, Buechel KL, Lambrecht LJ, et al. Effect of cyclooxygenase-2 inhibition on renal function in elderly persons receiving a low-salt diet. Ann Intern Med. (2000) 133:1. doi: 10.7326/0003-4819-133-1-200007040-00002

31. Markowitz GS, Perazella MA. Drug-induced renal failure: a focus on tubulointerstitial disease. Clin Chim Acta. (2005) 351:31-47. doi: 10.1016/j.cccn.2004.09.005

32. Perazella MA, Markowitz GS. Drug-induced acute interstitial nephritis. Nat Rev Nephrol. (2010) 6:461-70. doi: 10.1038/nrneph.2010.71

33. Leonard CE, Freeman CP, Newcomb CW, Reese PP, Herlim M, Bilker WB, et al. Proton pump inhibitors and traditional nonsteroidal anti-inflammatory drugs and the risk of acute interstitial nephritis and acute kidney injury. Pharmacoepidemiol Drug Saf. (2012) 21:1155-72. doi: 10.1002/pds.3329

34. Arora P, Rajagopalam S, Ranjan R, Kolli H, Singh M, Venuto R, et al. Preoperative use of angiotensin-converting enzyme inhibitors/angiotensin receptor blockers is associated with increased risk for acute kidney injury after cardiovascular surgery. Clin J Am Soc Nephrol. (2008) 3:126673. doi: 10.2215/CJN.05271107

35. Roshanov PS, Rochwerg B, Patel A, Salehian O, Duceppe E, Belley-Côté $\mathrm{EP}$, et al. Withholding versus continuing angiotensin-converting enzyme inhibitors or angiotensin II receptor blockers before noncardiac surgery. Anesthesiology. (2017) 126:16-27. doi: 10.1097/ALN.0000000000001404

36. Tomlinson LA, Abel GA, Chaudhry AN, Tomson CR, Wilkinson IB, Roland $\mathrm{MO}$, et al. ACE inhibitor and angiotensin receptor-II antagonist prescribing and hospital admissions with acute kidney injury: a longitudinal ecological study. PLoS One. (2013) 8:e78465. doi: 10.1371/journal.pone.0078465

37. Shah M, Jain AK, Brunelli SM, Coca SG, Devereaux PJ, James MT, et al. Association between angiotensin converting enzyme inhibitor or angiotensin receptor blocker use prior to major elective surgery and the risk of acute dialysis. BMC Nephrol. (2014) 15:53. doi: 10.1186/1471-2369-15-53

38. Bell S, Davey P, Nathwani D, Marwick C, Vadiveloo T, Sneddon J, et al. Risk of AKI with gentamicin as surgical prophylaxis. J Am Soc Nephrol. (2014) 25:2625-32. doi: 10.1681/ASN.2014010035

39. Elyasi S, Khalili H, Dashti-Khavidaki S, Mohammadpour A. Vancomycininduced nephrotoxicity: mechanism, incidence, risk factors and special populations. a literature review. Eur J Clin Pharmacol. (2012) 68:124355. doi: 10.1007/s00228-012-1259-9 
40. Bird ST, Etminan M, Brophy JM, Hartzema AG, Delaney JAC. Risk of acute kidney injury associated with the use of fluoroquinolones. Can Med Assoc J. (2013) 185:E475-82. doi: 10.1503/cmaj.121730

41. Muriithi AK, Leung N, Valeri AM, Cornell LD, Sethi S, Fidler ME, et al. Biopsy-proven acute interstitial nephritis, 1993-2011: a case series. Am J Kidney Dis. (2014) 64:558-66. doi: 10.1053/j.ajkd.2014.04.027

42. Rokushima M, Fujisawa K, Furukawa N, Itoh F, Yanagimoto T, Fukushima $\mathrm{R}$, et al. Transcriptomic analysis of nephrotoxicity induced by cephaloridine, a representative cephalosporin antibiotic. Chem Res Toxicol. (2008) 21:118696. doi: 10.1021/tx800008e

43. Chong E, Shen L, Poh KK, Tan HC. Risk scoring system for prediction of contrast-induced nephropathy in patients with pre-existing renal impairment undergoing percutaneous coronary intervention. Singapore Med J. (2012) 53:164-9.

44. McDonald JS, McDonald RJ, Carter RE, Katzberg RW, Kallmes DF, Williamson EE. Risk of intravenous contrast material-mediated acute kidney injury: a propensity score-matched study stratified by baseline-estimated glomerular filtration rate. Radiology. (2014) 271:65-73. doi: 10.1148/radiol.13130775

45. Dong M, Jiao Z, Liu T, Guo F, Li G. Effect of administration route on the renal safety of contrast agents: a meta-analysis of randomized controlled trials. $J$ Nephrol. (2012) 25:290-301. doi: 10.5301/jn.5000067

46. Caspi O, Habib M, Cohen Y, Kerner A, Roguin A, Abergel E, et al. Acute kidney injury after primary angioplasty: is contrast-induced nephropathy the culprit? J Am Heart Assoc. (2017) 6:e005715. doi: 10.1161/JAHA.117.005715

47. Yamauchi T, Miyagawa S, Yoshikawa Y, Toda K, Sawa Y. Risk index for postoperative acute kidney injury after valvular surgery using cardiopulmonary bypass: a propensity score analysis of 998 consecutive patients. Ann Thorac Surg. (2017) 104:868-75. doi: 10.1016/j.athoracsur.2017.02.012

48. Hilmi IA, Damian D, Al-Khafaji A, Planinsic R, Boucek C, Sakai T, et al. Acute kidney injury following orthotopic liver transplantation: incidence, risk factors, and effects on patient and graft outcomes. Br J Anaesth. (2015) 114:919-26. doi: 10.1093/bja/aeu556

49. Saratzis A, Melas N, Mahmood A, Sarafidis P. Incidence of acute kidney injury (AKI) after endovascular abdominal aortic aneurysm repair (EVAR) and impact on outcome. J Vasc Surg. (2015) 61:1378. doi: 10.1016/j.jvs.2015.03.058

50. Tang Y, Chen J, Huang K, Luo D, Liang P, Feng M, et al. The incidence, risk factors and in-hospital mortality of acute kidney injury in patients after abdominal aortic aneurysm repair surgery. BMC Nephrol. (2017) 18:184. doi: 10.1186/s12882-017-0594-6

51. Zhang C, Wang G, Zhou H, Lei G, Yang L, Fang Z, et al. Preoperative platelet count, preoperative hemoglobin concentration and deep hypothermic circulatory arrest duration are risk factors for acute kidney injury after pulmonary endarterectomy: a retrospective cohort study. J Cardiothorac Surg. (2019) 14:220. doi: 10.1186/s13019-019-1026-4

52. Sun LY, Wijeysundera DN, Tait GA, Beattie WS. Association of intraoperative hypotension with acute kidney injury after elective noncardiac surgery. Anesthesiology. (2015) 123:51523. doi: $10.1097 /$ ALN.0000000000000765

53. Rodgers A, Walker N, Schug S, McKee A, Kehlet H, van Zundert A, et al. Reduction of postoperative mortality and morbidity with epidural or spinal anaesthesia: results from overview of randomised trials. BMJ. (2000) 321:1493. doi: 10.1136/bmj.321.7275.1493

54. Kong HY, Zhu SM, Wang LQ, He Y, Xie HY, Zheng SS. Sevoflurane protects against acute kidney injury in a small-size liver transplantation model. Am J Nephrol. (2010) 32:347-55. doi: 10.1159/000319623

55. Bang JY, Lee J, Oh J, Song JG, Hwang GS. The influence of propofol and sevoflurane on acute kidney injury after colorectal surgery. Anesth Analg. (2016) 123:363-70. doi: 10.1213/ANE.0000000000001274

56. Zheng G, Qu H, Li F, Ma W, Yang H. Propofol attenuates sepsis-induced acute kidney injury by regulating miR-290-5p/CCL-2 signaling pathway. Braz J Med Biol Res. (2018) 51:e7655. doi: 10.1590/1414-431×20187655

57. Walsh M, Garg AX, Devereaux PJ, Argalious M, Honar H, Sessler DI. The association between perioperative hemoglobin and acute kidney injury in patients having noncardiac surgery. Anesth Analg. (2013) 117:92431. doi: 10.1213/ANE.0b013e3182alec 84
58. Karkouti K, Wijeysundera DN, Yau TM, McCluskey SA, Chan CT, Wong PY, et al. Influence of erythrocyte transfusion on the risk of acute kidney injury after cardiac surgery differs in anemic and nonanemic patients. Anesthesiology. (2011) 115:523-30. doi: 10.1097/ALN.0b013e31822 $9 \mathrm{a} 7 \mathrm{e} 8$

59. Murphy GJ, Reeves BC, Rogers CA, Rizvi SIA, Culliford L, Angelini GD. Increased mortality, postoperative morbidity, and cost after red blood cell transfusion in patients having cardiac surgery. Circulation. (2007) 116:254452. doi: 10.1161/CIRCULATIONAHA.107.698977

60. Koch CG, Li L, Duncan AI, Mihaljevic T, Cosgrove DM, Loop FD, et al. Morbidity and mortality risk associated with red blood cell and blood-component transfusion in isolated coronary artery bypass grafting. Crit Care Med. (2006) 34:1608-16. doi: 10.1097/01.CCM.0000217920. 48559.D8

61. Abelha FJ, Botelho M, Fernandes V, Barros H. Determinants of postoperative acute kidney injury. Crit Care. (2009) 13:R79. doi: 10.1186/cc7894

62. Sim JH, Jun IG, Moon YJ, Jeon AR, Kim SH, Kim B, et al. Association of preoperative prognostic nutritional index and postoperative acute kidney injury in patients who underwent hepatectomy for hepatocellular carcinoma. J Pers Med. (2021) 11:428. doi: 10.3390/jpm11050428

63. Sim JH, Bang JY, Kim SH, Kang SJ, Song JG. Association of preoperative prognostic nutritional index and postoperative acute kidney injury in patients with colorectal cancer surgery. Nutrients. (2021) 13:1604. doi: 10.3390/nu13051604

64. Zhang Y, Jiang L, Wang B, Xi X. Epidemiological characteristics of and risk factors for patients with postoperative acute kidney injury: a multicenter prospective study in 30 Chinese intensive care units. Int Urol Nephrol. (2018) 50:1319-28. doi: 10.1007/s11255-018-1828-7

65. Ma Y, Fang K, Gang S, Peng J, Jiang L, He F, et al. Occurrence and predictive factors of acute renal injury following hip and knee arthroplasty. Clin Exp Nephrol. (2020) 24:598-605. doi: 10.1007/s10157-020-01874-z

66. Perazella MA, Tray K. Selective cyclooxygenase-2 inhibitors: a pattern of nephrotoxicity similar to traditional nonsteroidal anti-inflammatory drugs. Am J Med. (2001) 111:64-7. doi: 10.1016/S0002-9343(01)00757-4

67. Baker M, Perazella MA. NSAIDs in CKD: are they safe? Am J Kidney Dis. (2020) 76:546-57. doi: 10.1053/j.ajkd.2020.03.023

68. STARSurg Collaborative. Association between peri-operative angiotensin-converting enzyme inhibitors and angiotensin-2 receptor blockers and acute kidney injury in major elective non-cardiac surgery: a multicentre, prospective cohort study. Anaesthesia. (2018) 73:1214-22. doi: 10.1016/j.ijsu.2018.05.703

69. Patek TM, Teng C, Kennedy KE, Alvarez CA, Frei CR. Comparing acute kidney injury reports among antibiotics: a pharmacovigilance study of the FDA Adverse Event Reporting System (FAERS). Drug Saf. (2020) 43:1722. doi: 10.1007/s40264-019-00873-8

70. Moledina DG, Perazella MA. Drug-induced acute interstitial nephritis. Clin J Am Soc Nephrol. (2017) 12:2046-9. doi: 10.2215/CJN.07630717

71. Khan M, Ortega LM, Bagwan N, Nayer A. Crystal-induced acute kidney injury due to ciprofloxacin. J Nephropathol. (2015) 4:29-31. doi: 10.12860/jnp.2015.06

72. Mac K, Chavada R, Paull S, Howlin K, Wong J. Cefepime induced acute interstitial nephritis-a case report. BMC Nephrol. (2015) 16:15. doi: 10.1186/s12882-015-0004-x

73. KIDGO, AKI Guideline: Section 4: contrast-induced AKI. Kidney Int Suppl. (2012) 2:69-88. doi: 10.1038/kisup.2011.34

74. Owen RJ, Hiremath S, Myers A, Fraser-Hill M, Barrett BJ. Canadian Association of Radiologists consensus guidelines for the prevention of contrast-induced nephropathy: update 2012. Can Assoc Radiol J. (2014) 65:96-05. doi: 10.1016/j.carj.2012.11.002

75. Keaney JJ, Hannon CM, Murray PT. Contrast-induced acute kidney injury: how much contrast is safe?. Nephrol Dial Transplant. (2013) 28:137683. doi: $10.1093 / \mathrm{ndt} / \mathrm{gfs} 602$

76. Fähling M, Seeliger E, Patzak A, Persson PB. Understanding and preventing contrast-induced acute kidney injury. Nat Rev Nephrol. (2017) 13:16980. doi: 10.1038/nrneph.2016.196

77. Azzalini L, Spagnoli V, Ly HQ. Contrast-induced nephropathy: from pathophysiology to preventive strategies. Can J Cardiol. (2016) 32:24755. doi: 10.1016/j.cjca.2015.05.013 
78. Feldkamp T, Kribben A. Contrast media induced nephropathy: definition, incidence, outcome, pathophysiology, risk factors and prevention. Minerva Med. (2008) 99:177-96.

79. Pistolesi V, Regolisti G, Morabito S, Gandolfini I, Corrado S, Piotti G, et al. Contrast medium induced acute kidney injury: a narrative review. J Nephrol. (2018) 31:797-812. doi: 10.1007/s40620-018-0498-y

80. Mamoulakis C, Tsarouhas K, Fragkiadoulaki I, Heretis I, Wilks MF, Spandidos DA, et al. Contrast-induced nephropathy: basic concepts, pathophysiological implications and prevention strategies. Pharmacol Ther. (2017) 180:99-112. doi: 10.1016/j.pharmthera.2017.06.009

81. Wilhelm-Leen E, Montez-Rath ME, Chertow G. Estimating the risk of radiocontrast-associated nephropathy. J Am Soc Nephrol. (2017) 28:6539. doi: 10.1681/ASN.2016010021

82. Jiang $\mathrm{Y}$, Chen $\mathrm{M}$, Zhang $\mathrm{Y}$, Zhang $\mathrm{N}$, Yang $\mathrm{H}$, Yao J, et al. Meta-analysis of prophylactic hydration versus no hydration on contrast-induced acute kidney injury. Coron Artery Dis. (2017) 28:649-57. doi: 10.1097/MCA.0000000000000514

83. Jang JS, Jin HY, Seo JS, Yang TH, Kim DK, Kim TH, et al. Sodium bicarbonate therapy for the prevention of contrast-induced acute kidney injury. Circ J. (2012) 76:2255-65. doi: 10.1253/circj.CJ-12-0096

84. Windecker S, Kolh P, Alfonso F, Collet J-P, Cremer J, Falk V, et al. 2014 ESC/EACTS Guidelines on myocardial revascularization: The Task Force on Myocardial Revascularization of the European Society of Cardiology (ESC) and the European Association for Cardio-Thoracic Surgery (EACTS)Developed with the special contribution of the European Association of Percutaneous Cardiovascular Interventions (EAPCI). Eur Heart J. (2014) 35:2541-619. doi: 10.1093/eurheartj/ehu278

85. Zhao SJ, Zhong ZS, Qi GX, Tian W. The efficacy of N-acetylcysteine plus sodium bicarbonate in the prevention of contrast-induced nephropathy after cardiac catheterization and percutaneous coronary intervention: a metaanalysis of randomized controlled trials. Int J Cardiol. (2016) 221:2519. doi: 10.1016/j.ijcard.2016.07.086

86. Xu R, Tao A, Bai Y, Deng Y, Chen G. Effectiveness of N-Acetylcysteine for the prevention of contrast-induced nephropathy: a systematic review and meta-analysis of randomized controlled trials. J Am Heart Assoc. (2016) 5:e003968. doi: 10.1161/JAHA.116.003968

87. Wang N, Qian P, Kumar S, Yan TD, Phan K. The effect of Nacetylcysteine on the incidence of contrast-induced kidney injury: a systematic review and trial sequential analysis. Int J Cardiol. (2016) 209:319327. doi: 10.1016/j.ijcard.2016.02.083

88. Lee JM, Park J, Jeon KH, Jung JH, Lee SE, Han JK, et al. Efficacy of short-term high-dose statin pretreatment in prevention of contrast-induced acute kidney injury: updated study-level metaanalysis of 13 randomized controlled trials. PLoS One. (2014) 9:e111397. doi: 10.1371/journal.pone.0111397

89. Gandhi S, Mosleh W, Abdel-Qadir H, Farkouh ME. Statins and contrastinduced acute kidney injury with coronary angiography. Am J Med. (2014) 127:987-1000. doi: 10.1016/j.amjmed.2014.05.011

90. Wang N, Qian P, Yan TD, Phan K. Periprocedural effects of statins on the incidence of contrast-induced acute kidney injury: a systematic review and trial sequential analysis. Int J Cardiol. (2016) 206:14352. doi: 10.1016/j.ijcard.2016.01.004

91. Li H, Wang C, Liu C, Li R, Zou M, Cheng G. Efficacy of short-term statin treatment for the prevention of contrast-induced acute kidney injury in patients undergoing coronary angiography/percutaneous coronary intervention: a meta-analysis of 21 randomized controlled trials. Am J Cardiovasc Drugs. (2016) 16:201-19. doi: 10.1007/s40256-016-0164-5

92. Bansal S, Wang W, Falk S, Schrier R. Combination therapy with albumin and pentoxifylline protects against acute kidney injury during endotoxemic shock in mice. Ren Fail. (2009) 31:848-54. doi: 10.3109/08860220903180632

93. Okumura AS, Rodrigues LE, Martinelli R. Pentoxifylline in ischemia-induced acute kidney injury in rats. Ren Fail. (2009) 31:829-32. doi: 10.3109/08860220903137509

94. Wei L, Zhang W, Yang Y, Li D. Pentoxifylline for the prevention of contrast-induced nephropathy: systematic review and metaanalysis of randomised controlled trials. BMJ Open. (2021) 11:e043436. doi: 10.1136/bmjopen-2020-043436
95. Yavari V, Ostovan MA, Kojuri J, Afshariani R, Hamidian A, Roozbeh J, et al. The preventive effect of pentoxifylline on contrast-induced nephropathy: a randomized clinical trial. Int Urol Nephrol. (2014) 46:416. doi: 10.1007/s11255-013-0420-4

96. O’Neal JB, Shaw AD, Billings FTT. Acute kidney injury following cardiac surgery: current understanding and future directions. Crit Care. (2016) 20:187. doi: 10.1186/s13054-016-1352-z

97. Kourliouros A, Valencia O, Phillips SD, Collinson PO, van Besouw JP, Jahangiri M. Low cardiopulmonary bypass perfusion temperatures are associated with acute kidney injury following coronary artery bypass surgery. Eur J Cardio-Thorac Surg. (2010) 37:704-9. doi: 10.1016/j.ejcts.2009.08.020

98. Vives M, Hernandez A, Parramon F, Estanyol N, Pardina B, Muñoz A, et al. Acute kidney injury after cardiac surgery: prevalence, impact and management challenges. Int J Nephrol Renovasc Dis. (2019) 12:15366. doi: 10.2147/IJNRD.S167477

99. Vercaemst L. Hemolysis in cardiac surgery patients undergoing cardiopulmonary bypass: a review in search of a treatment algorithm. J Extra Corpor Technol. (2008) 40:257-67.

100. Reents W, Hilker M, Börgermann J, Albert M, Plötze K, Zacher M, et al. Acute kidney injury after on-pump or off-pump coronary artery bypass grafting in elderly patients. Ann Thorac Surg. (2014) 98:915. doi: 10.1016/j.athoracsur.2014.01.088

101. Sang BH, Bang JY, Song JG, Hwang GS. Hypoalbuminemia within two postoperative days is an independent risk factor for acute kidney injury following living donor liver transplantation. Crit Care Med. (2015) 43:255261. doi: 10.1097/CCM.0000000000001279

102. Nash DM, Mustafa RA, McArthur E, Wijeysundera DN, Paterson JM, Sharan S, et al. Combined general and neuraxial anesthesia versus general anesthesia: a population-based cohort study. Can J Anesth. (2015) 62:35668. doi: 10.1007/s12630-015-0315-1

103. Karkouti K, Wijeysundera DN, Yau TM, Callum JL, Cheng $\mathrm{DC}$, Crowther $\mathrm{M}$, et al. Acute kidney injury after cardiac surgery: focus on modifiable risk factors. Circulation. (2009) 119:495-502. doi: 10.1161/CIRCULATIONAHA.108.786913

104. Estrella MM, Astor BC, Köttgen A, Selvin E, Coresh J, Parekh RS. Prevalence of kidney disease in anaemia differs by GFR-estimating method: the Third National Health and Nutrition Examination Survey (1988-94). Nephrol Dial Transplant. (2010) 25:2542-8. doi: 10.1093/ndt/gfq040

105. Lasocki S, Longrois D, Montravers P, Beaumont C, Riou B. Hepcidin and anemia of the critically ill patient. Anesthesiology. (2011) 114:68894. doi: 10.1097/ALN.0b013e3182065c57

106. Penny-Dimri JC, Cochrane AD, Perry LA, Smith JA. Characterising the role of perioperative erythropoietin for preventing acute kidney injury after cardiac surgery: systematic review and meta-analysis. Heart Lung Circ. (2016) 25:1067-76. doi: 10.1016/j.hlc.2016.04.016

107. Li C, Xu L, Guan C, Zhao L, Luo C, Zhou B, et al. Malnutrition screening and acute kidney injury in hospitalised patients: a retrospective study over a 5-year period from China. Br J Nutr. (2020) 123:33746. doi: 10.1017/S000711451900271X

108. Benabe JE, Martinez-Maldonado M. The impact of malnutrition on kidney function. Miner Electrolyte Metab. (1998) 24:20-6. doi: 10.1159/000057346

109. Toigo G, Aparicio M, Attman PO, Cano N, Cianciaruso B, Engel B, et al. Expert Working Group report on nutrition in adult patients with renal insufficiency (part 1 of 2). Clin Nutr. (2000) 19:197207. doi: 10.1054/clnu.1999.0130

110. Li N, Qiao H, Guo JF, Yang HY, Li XY, Li SL, et al. Preoperative hypoalbuminemia was associated with acute kidney injury in high-risk patients following non-cardiac surgery: a retrospective cohort study. BMC Anesthesiol. (2019) 19:171. doi: 10.1186/s12871-019-0842-3

111. Zapatero A, Dot I, Diaz Y, Gracia MP, Pérez-Terán P, Climent C, et al. Severe vitamin D deficiency upon admission in critically ill patients is related to acute kidney injury and a poor prognosis. Med Intensiva. (2018) 42:216-24. doi: 10.1016/j.medine.2017.07.002

112. Hsu CY, Huang YH, Su CW, Lin HC, Chiang JH, Lee PC, et al. Renal failure in patients with hepatocellular carcinoma and ascites undergoing transarterial chemoembolization. Liver Int. (2010) 30:7784. doi: 10.1111/j.1478-3231.2009.02128.x 
113. Ostermann M, Summers J, Lei K, Card D, Harrington DJ, Sherwood R, et al. Micronutrients in critically ill patients with severe acute kidney injury - a prospective study. Sci Rep. (2020) 10:1505. doi: 10.1038/s41598-02058115-2

114. Zorrilla-Vaca A, Mena GE, Ripolles-Melchor J, Lorente JV, RamirezRodriguez JJM, Grant MC. Risk factors for acute kidney injury in an enhanced recovery pathway for colorectal surgery. Surg Today. (2021) 51:537-44. doi: 10.1007/s00595-020-02107-2

115. Brienza N, Giglio MT, Marucci M, Fiore T. Does perioperative hemodynamic optimization protect renal function in surgical patients? A meta-analytic study. Crit Care Med. (2009) 37:207990. doi: 10.1097/CCM.0b013e3181a00a43

116. Yunos NM, Bellomo R, Hegarty C, Story D, Ho L, Bailey M. Association between a chloride-liberal vs chloride-restrictive intravenous fluid administration strategy and kidney injury in critically ill adults. JAMA. (2012) 308:1566-72. doi: 10.1001/jama.2012.13356

117. Hartog CS, Natanson C, Sun J, Klein HG, Reinhart K. Concerns over use of hydroxyethyl starch solutions. BMJ. (2014) 349:g5981. doi: 10.1136/bmj.g5981

118. Bayer O, Schwarzkopf D, Doenst T, Cook D, Kabisch B, Schelenz C, et al. Perioperative fluid therapy with tetrastarch and gelatin in cardiac surgery-a prospective sequential analysis*. Crit Care Med. (2013) 41:253242. doi: 10.1097/CCM.0b013e3182978fb6

119. Gillies MA, Habicher M, Jhanji S, Sander M, Mythen M, Hamilton M, et al. Incidence of postoperative death and acute kidney injury associated with i.v. $6 \%$ hydroxyethyl starch use: systematic review and meta-analysis. $\mathrm{Br} \mathrm{J}$ Anaesth. (2014) 112:25-34. doi: 10.1093/bja/aet303

120. Joannidis M, Druml W, Forni LG, Groeneveld ABJ, Honore R, Ronco C, et al. Prevention of acute kidney injury and protection of renal function in the intensive care unit. expert opinion of the working group for nephrology. Intensive Care Med. (2010) 36:392-411. doi: 10.1007/s00134-0091678-y

121. Kork F, Eltzschig HK. The devil is in the detail: remote ischemic preconditioning for perioperative kidney protection. Anesthesiology. (2017) 126:763-5. doi: 10.1097/ALN.0000000000001599

122. Zarbock A, Kellum JA, Van Aken H, Schmidt C, Küllmar M, Rosenberger $P$, et al. Long-term effects of remote ischemic preconditioning on kidney function in high-risk cardiac surgery patients: follow-up results from the RenalRIP trial. Anesthesiology. (2017) 126:787-98. doi: 10.1097/ALN.0000000000001598

123. Long YQ, Feng XM, Shan XS, Chen QC, Xia ZY, Ji FH, et al. Remote ischemic preconditioning reduces acute kidney injury after cardiac surgery: a systematic review and meta-analysis of randomized controlled trials. Anesth Analg. (2021). doi: 10.1213/ANE.0000000000005804. [Epub ahead of print].

124. Liu Z, Zhao Y, Lei M, Zhao GC, Li DC, Sun R, et al. Remote ischemic preconditioning to prevent acute kidney injury after cardiac surgery: a meta-analysis of randomized controlled trials. Front Cardiovasc Med. (2021) 8:601470. doi: 10.3389/fcvm.2021.601470

125. Hausenloy DJ, Candilio L, Evans R, Ariti C, Jenkins DP, Kolvekar S, et al. Remote ischemic preconditioning and outcomes of cardiac surgery. $N$ Engl J Med. (2015) 373:1408-17. doi: 10.1056/NEJMoa1413534

126. Wahlstrøm KL, Bjerrum E, Gögenur I, Burcharth J, Ekeloef S. Effect of remote ischaemic preconditioning on mortality and morbidity after non-cardiac surgery: meta-analysis. BJS Open. (2021) 5:zraa026. doi: 10.1093/bjsopen/zraa026

127. Molnar AO, Coca SG, Devereaux PJ, Jain AK, Kitchlu A, Luo J, et al. Statin use associates with a lower incidence of acute kidney injury after major elective surgery. J Am Soc Nephrol. (2011) 22:93946. doi: 10.1681/ASN.2010050442
128. Park JH, Shim JK, Song JW, Soh S, Kwak YL. Effect of atorvastatin on the incidence of acute kidney injury following valvular heart surgery: a randomized, placebo-controlled trial. Intensive Care Med. (2016) 42:1398407. doi: 10.1007/s00134-016-4358-8

129. Billings FTT, Hendricks PA, Schildcrout JS, Shi Y, Petracek MR, Byrne JG, et al. High-dose perioperative atorvastatin and acute kidney injury following cardiac surgery: a randomized clinical trial. JAMA. (2016) 315:87788. doi: 10.1001/jama.2016.0548

130. Sessler DI, Bloomstone JA, Aronson S, Berry C, Gan TJ, Kellum JA, et al. Perioperative quality initiative consensus statement on intraoperative blood pressure, risk and outcomes for elective surgery. Br J Anaesth. (2019) 122:563-74. doi: 10.1016/j.bja.2019.01.013

131. Mathis MR, Naik BI, Freundlich RE, Shanks AM, Heung M, Kin $\mathrm{M}$, et al. Preoperative risk and the association between hypotension and postoperative acute kidney injury. Anesthesiology. (2020) 132:46175. doi: 10.1097/ALN.0000000000003063

132. Kwiatkowski DM, Axelrod DM, Sutherland SM, Tesoro TM, Krawczeski CD. Dexmedetomidine is associated with lower incidence of acute kidney injury after congenital heart surgery. Pediatric Crit Care Med. (2016) 17:12834. doi: 10.1097/PCC.0000000000000611

133. Shi R, Tie HT. Dexmedetomidine as a promising prevention strategy for cardiac surgery-associated acute kidney injury: a meta-analysis. Crit Care. (2017) 21:198. doi: 10.1186/s13054-017-1776-0

134. Loomba RS, Villarreal EG, Dhargalkar J, Rausa J, Dorsey V, Farias JS, et al. The effect of dexmedetomidine on renal function after surgery: a systematic review and meta-analysis. J Clin Pharm Ther. (2021). doi: 10.1111/jcpt.13527. [Epub ahead of print].

135. Bagshaw SM, Gibney RTN, Kruger P, Hassan I, McAlister FA, Bellomo R. The effect of low-dose furosemide in critically ill patients with early acute kidney injury: a pilot randomized blinded controlled trial (the SPARK study). J Crit Care. (2017) 42:138-46. doi: 10.1016/j.jcrc.2017.07.030

136. Krzych ŁJ, Czempik PF. Impact of furosemide on mortality and the requirement for renal replacement therapy in acute kidney injury: a systematic review and meta-analysis of randomised trials. Ann Intensive Care. (2019) 9:85. doi: 10.1186/s13613-019-0557-0

137. Khwaja A. KDIGO clinical practice guidelines for acute kidney injury. Nephron Clin Pract. (2012) 120:c179-84. doi: 10.1159/000339789

138. Gaudry S, Hajage D, Schortgen F, Martin-Lefevre L, Pons B, Boulet E, et al. Initiation strategies for renal-replacement therapy in the intensive care unit. N Engl J Med. (2016) 375:122-33. doi: 10.1056/NEJMoa1603017

139. Zarbock A, Mehta RL. Timing of kidney replacement therapy in acute kidney injury. Clin J Am Soc Nephrol. (2019) 14:147-9. doi: 10.2215/CJN.08810718

Conflict of Interest: The authors declare that the research was conducted in the absence of any commercial or financial relationships that could be construed as a potential conflict of interest.

Publisher's Note: All claims expressed in this article are solely those of the authors and do not necessarily represent those of their affiliated organizations, or those of the publisher, the editors and the reviewers. Any product that may be evaluated in this article, or claim that may be made by its manufacturer, is not guaranteed or endorsed by the publisher.

Copyright (C) $2021 \mathrm{Yu}$ and Feng. This is an open-access article distributed under the terms of the Creative Commons Attribution License (CC BY). The use, distribution or reproduction in other forums is permitted, provided the original author(s) and the copyright owner(s) are credited and that the original publication in this journal is cited, in accordance with accepted academic practice. No use, distribution or reproduction is permitted which does not comply with these terms. 